\title{
Commentary: Timing is everything!
}

Jay K. Bhama, MD

\author{
From the Department of Cardiothoracic Surgery and Heart Failure \& Transplant Institute, Baptist Health Medical \\ Center, Little Rock, Ark. \\ Disclosures: Author has nothing to disclose with regard to commercial support. \\ Received for publication Jan 31, 2019; accepted for publication Feb 1, 2019. \\ Address for reprints: Jay K. Bhama, MD, Department of Cardiothoracic Surgery and Heart Failure \& Transplant \\ Institute, Baptist Health Medical Center, 9601 Baptist Health Drive, Suite 990, Little Rock, AR 72205 (E-mail: \\ jay-bhama@uiowa.edu). \\ J Thorac Cardiovasc Surg 2019;157:2325-6 \\ $0022-5223 / \$ 36.00$ \\ Copyright $(C) 2019$ by The American Association for Thoracic Surgery \\ https://doi.org/10.1016/j.jtcvs.2019.02.003
}

\section{Good luck and good timing are the same thing.} -Attributed to the Maharishi Mahesh Yogi

"Good luck" is something we commonly say to wish someone well in an endeavor that may be challenging, and sometimes even when no particular challenge is expected. For surgeons, probably the most frequent utterance of this phrase is to a colleague before starting a surgical procedure, or perhaps to a family member before embarking on a journey or before participating in an important event at work or school. Good luck is something we all hope for, and many of us even pray for.

In this issue of the Journal, Brown and colleagues ${ }^{1}$ from the University of Pennsylvania report on an important investigation regarding the effect of left ventricular assist device (LVAD) bridge-to-transplant duration (ie, time on device support) on outcomes of heart transplantation. In an analysis of data derived from the Medicare database, Brown and colleagues ${ }^{1}$ demonstrated that all-cause mortality was significantly worse for patients who were bridged for less than 31 days. Furthermore, they determined that 3-year mortality was improved in patients with longer LVAD support durations (31-365 days and $>365$ days) and in those without LVAD support relative to patients supported for less than 31 days. Risk factors associated with 30-day and 3-year mortalities included pretransplant renal insufficiency, pneumonia, and occurrence of a major bleeding event in the 30 days before transplantation. Brown and colleagues ${ }^{1}$ found the highest risk period to be between 4 and 34 days after initiation of device support. In addition to these findings related to mortality, Brown and colleagues ${ }^{1}$ demonstrated that major complications, such as the need for tracheostomy, the need for hemodialysis, sepsis, acute kidney injury, and postoperative bleeding, were higher in patients who underwent transplant early after initiation of device support. Not surprisingly, those patients had an almost 3-fold longer hospital stay.

The University of Pennsylvania investigators ${ }^{1}$ are to be commended for their efforts to elucidate the impact of

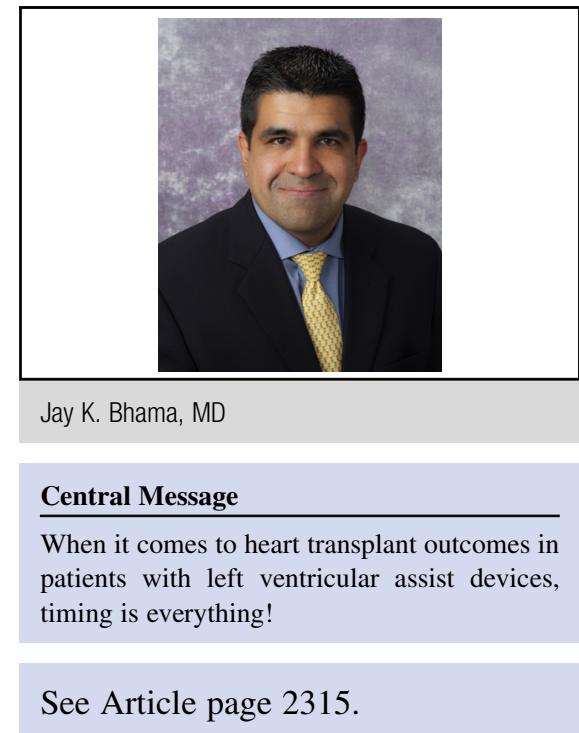

transplant timing on outcomes after bridge-to-transplant LVAD therapy. As the heart transplant programs in the United States adjust to the new organ allocation system, which prioritizes patients on short-term mechanical circulatory support and extracorporeal membrane oxygenation, as opposed to durable LVAD therapy, the type of data presented in this study will become increasing important as a benchmark against which to compare contemporary data. Historically, it has always been an accepted paradigm that heart transplantation in the setting of acute illness is predictably high risk, and that patients benefit from stabilization on durable devices. This study provides important insight into the optimal timing for transplantation after durable LVAD support initiation, highlighting a very clear and concerning risk for mortality among patients who undergo transplant within the first month after LVAD placement. A parallel may be drawn between these patients, who are just recovering from the impact of major surgery for LVAD implantation, and those with a higher burden of acute illness awaiting heart transplant with the aid of temporary mechanical support devices or extracorporeal membrane oxygenation. As the pendulum swings toward performing heart transplantation in this sicker population of patients, these data should serve as a wake-up call for cardiologists and surgeons alike, highlighting as they do the potential of the new organ allocation system to affect the most important aspect of our responsibility to that precious resource, namely, graft survival.

Brown and colleagues ${ }^{1}$ ask an important question in the title to their article: Is timing of the essence? If we are to 
believe the Maharishi's words about good luck and good timing, then we should all agree that when it comes to heart transplantation in this population of patients, timing is everything!

\section{Reference}

1. Brown CR, Khurshan F, Chen Z, Groeneveld PW, McCarthy F, Acker M, et al. Optimal timing for heart transplantation in patients bridged with left ventricular assist devices: is timing of the essence? J Thorac Cardiovasc Surg. 2019;157: 2315-24.e4. 